\title{
Functional Impact of Tinnitus in Patients with Hearing Loss
}

\author{
Erika Barioni Mantello ${ }^{10}$ \\ Juliana Maria Soares Cavalcante 4 Eduardo Tanaka Mas

\footnotetext{
${ }^{1}$ Speech, Language and Hearing Department, Universidade Federal do Rio Grande do Norte (UFRN), Natal, RN, Brazil

${ }^{2}$ Clinical Speech, Language and Hearing Department, Pontifícia Universidade Católica, São Paulo, SP, Brazil

3 Speech Therapist Graduated, Faculdade de Medicina de Ribeirão Preto, Universidade de São Paulo, SP, Brazil

${ }^{4}$ Department of Health Sciences, Faculdade de Medicina de Ribeirão Preto, Universidade de São Paulo, SP, São Paulo, Brazil

${ }^{5}$ Department of Ophthalmology, Otorhinolaryngology, and Head and Neck Surgery, Faculdade de Medicina de Ribeirão Preto,

Universidade de São Paulo, Ribeirão Preto, SP, Brazil
}

Paula Cantarella de Padua Rodrigues ${ }^{3}$

Adriana Ribeiro Tavares Anastasio 4
Address for correspondence Erika Barioni Mantello, PhD, Departamento de Fonoaudiologia, Centro de Ciências da Saúde, Universidade Federal do Rio Grande do Norte (UFRN), Rua General Gustavo Cordeiro de Faria, s/n, Petrópolis, Natal, RN, 59012-570, Brasil (e-mail: erikafga@yahoo.com.br).

\begin{abstract}
Keywords

- tinnitus

- hearing loss

- questionnaires

- quality of life

Introduction Tinnitus, which is considered the third worst symptom for humans, is a common complaint among people living with hearing loss and may negatively affect the quality of life of those who have it.

Objective To analyze the perception of the handicap in patients with tinnitus and hearing loss as well as the possible associations between the variables hearing loss, loudness, onset, frequency and annoyance by tinnitus, and the correlation between the visual analogue scale (VAS) and the Tinnitus Handicap Inventory (THI).

Methods A total of 30 patients with complaints of tinnitus and the presence of sensorineural hearing impairment were selected for this cross-sectional, observational, and descriptive study. The loudness of the tinnitus was measured by a VAS and classified as mild, moderate, or severe. The THI was classified as slight, mild, moderate, severe, and catastrophic. Data were submitted to statistical analysis using the Fisher exact test and Spearman correlation coefficient.

Results Eleven male (36.7\%) and 19 female (63.3\%) subjects with a mean age of 56.5 years old were evaluated. There was no significant association between loudness, annoyance, time and frequency of tinnitus, nor between hearing loss and tinnitus. There was a significant association between the variables hearing loss and loudness, and a weak correlation between VAS and THI.

Conclusion Tinnitus has a practical impact in the lives of patients with hearing loss in terms of catastrophic, functional, and emotional aspects, regardless of loudness, frequency, or time of onset. Hearing loss was a factor that had an impact on the loudness of tinnitus. There was no statistically significant correlation between VAS and THI.
\end{abstract}

received

October 30, 2018

accepted

August 11, 2019
DOI https://doi.org/

10.1055/s-0039-1697994. ISSN 1809-9777.
Copyright $\odot 2020$ by Thieme Revinter

Publicações Ltda, Rio de Janeiro, Brazil
License terms

(ㄷ) (i) $\ominus$ (5) 


\section{Introduction}

Tinnitus is the sound sensation perceived by a sole individual regardless of the external sound stimulus. Tinnitus is not a disease but a symptom. It is considered the third worst symptom for humans, only surpassed by intense and intractable pain and dizziness. ${ }^{1,2}$ There is no concrete statistical data about the prevalence of tinnitus in Brazil. However, it is believed that more than 28 million Brazilians experience tinnitus at some stage of their lives. ${ }^{3,4}$

Several impairments are associated with the presence of tinnitus, such as failure in reasoning, memory, and concentration. These alterations can influence negatively the quality of life of the individuals affected by tinnitus, and there are reports in the literature on the association of these alterations impairing work and leisure activities, rest time, communication, both in the social and domestic environments, with repercussions on the psychic sphere, causing people to be irritable, anxious, distressed, depressed, and insomniac. ${ }^{5-9}$

The measurement of tinnitus is still a very controversial topic, and there is no standardized measure widely used in the audiological routine. Although otoneurological and psychoacoustic tests may aid in the clinical diagnosis and choice of treatment, they are not sensitive or specific tests to measure the quality of life (QoL) impairment due to tinnitus.

However, there are subjective assessment tools available in Portuguese, such as the Hospital Anxiety and Depression Scale (HADS), most commonly used to detect symptoms of depression, due to its easy applicability. ${ }^{10-12}$ As tinnitus is a subjective symptom, it is difficult to analyze, evaluate and treat. Assessment instruments, such as acuphenometry and, aisual analogue scale (VAS), and questionnaires to determine the impact of tinnitus, such as the Tinnitus Handicap Inventory (THI), are important tools in addition to individual approaches in the treatment of patients afflicted by tinnitus. ${ }^{9,13-15}$

The THI is a specific questionnaire to evaluate the emotional, functional, and catastrophic aspects triggered by tinnitus. ${ }^{9,16,17}$ Ferreira et $\mathrm{al}^{14}$ and Schmidt et $\mathrm{al}^{18}$ adapted the THI to the Portuguese language determining its reproducibility and validity. The Brazilian version of the THI was considered a reliable, valid and reproducible instrument for the verification of impairment in the quality of life caused by tinnitus. ${ }^{14}$

Tinnitus is a constant complaint in the medical and speech-language clinics, and its association with hearing loss is reported by 85 to $96 \%$ of patients. Tinnitus from the sensorineural hearing system presents more complex pathophysiology, making it more distressing to the patient and challenging for the clinician. ${ }^{19,20}$ Some studies show a relationship between the severity of tinnitus and the degree of hearing loss. ${ }^{21,22}$ Baskill and Coles ${ }^{23}$ believe that the influence of the degree of hearing loss on the severity of tinnitus is still uncertain, as they found the correlation between auditory thresholds and annoyance by tinnitus to be weak.

Numerous authors have described the repercussion of tinnitus on the individual's quality of life. The adverse effects caused by tinnitus on the quality of life of the subjects may be reduced, even there is no effective cure. ${ }^{24}$ Scientific knowledge about tinnitus variables is essential to provide subsidies that help the evaluation and decision on the most appropriate clinical treatment; and studies that address the impact of tinnitus are useful for promoting the quality of life of the individuals affected.

Thus, the aim of this study was to analyze the perception of the handicap in patients with tinnitus and hearing loss, as well as the possible associations between the variables hearing loss, loudness, onset, frequency and annoyance by tinnitus, and the correlation between the VAS and the THI.

\section{Material and Methods}

The study was approved by the research ethics committee of the institution (process number 8733/2008), and a written informed consent was obtained from all participants. It is an observational, descriptive and cross-sectional study that recruited 30 patients, obtained from a convenience sample that attended the Tinnitus Outpatient Clinic of a general hospital for 18 months.

The inclusion criteria were patients of both genders, with a current complaint of tinnitus, older than 18 years old, who presented unilateral or bilateral sensorineural hearing loss, regardless of the degree of hearing loss, and who were being followed at the institution's tinnitus outpatient clinic. Patients with conductive hearing loss and history of cognitive problems or psychiatric diseases that could affect their quality of life were excluded. An interview for the collection of personal, demographic, and hearing loss and tinnitus aspects of the patient was conducted.

The loudness of tinnitus was evaluated by VAS. For this, the patient received a blank sheet of paper containing a continuous line, written, "no tinnitus" at one end, and "maximum tinnitus" at the other. The researcher asked the patient: "Today, how loud is your tinnitus?" and requested the patient to mark a dot on the continuous line, according to his|her sensation. The patient was advised that the left extremity corresponded to no tinnitus sensation, and the right end to the maximum tinnitus sensation. The patient was not aware that the continuous line had $100 \mathrm{~mm}$, in which $0 \mathrm{~mm}$ corresponded to "no tinnitus" and $100 \mathrm{~mm}$ corresponded to "maximum tinnitus." 25 The quantification of tinnitus loudness as per the VAS was classified as mild $(0-39 \mathrm{~mm})$, moderate $(40-79 \mathrm{~mm})$, and severe $(80-$ $100 \mathrm{~mm}) .{ }^{26}$ After the use of VAS, the Brazilian version of the THI questionnaire was applied. ${ }^{14}$ In the application, each question was read orally by the researcher to include those patients with visual impairment or illiteracy. The patients were interviewed individually.

The Brazilian version of the THI is composed of 25 questions, divided into 3 scales. Functional (F) measures the annoyance caused by tinnitus in mental, social, occupational, and physical functions. The emotional (E) scale measures affective responses, such as anxiety, anger, and depression. The catastrophic (C) scale quantifies the despair and inability referred to by the affected person to live with or get rid of the symptom. ${ }^{14}$

The possible answers are "yes," "no," and "sometimes," receiving respectively four points, zero points, and two points. The questions are divided into 11 questions for the F scale, 9 questions for the $\mathrm{E}$ scale, and 5 questions for the $\mathrm{C}$ 
Table 1 Characterization of tinnitus in the studied sample ( $n=30$ ) according to the affected site, frequency, onset of symptom, and number of perceived sounds

\begin{tabular}{|l|l|}
\hline Item & Percentage of patients \\
\hline $\begin{array}{l}\text { Site affected } \\
\text { by tinnitus }\end{array}$ & $\begin{array}{l}\text { Unilateral right - 13\% } \\
\text { Unilateral left - 20\% } \\
\text { Bilateral }-60 \% \\
\text { Head - 7\% }\end{array}$ \\
\hline $\begin{array}{l}\text { Frequency } \\
\text { of tinnitus }\end{array}$ & $\begin{array}{l}\text { Sometimes }-7 \% \\
\text { Often }-10 \% \\
\text { Always }-80 \% \\
\text { Do not know how to refer }-3 \%\end{array}$ \\
\hline Onset of tinnitus & $\begin{array}{l}<5 \text { years }-53 \% \\
\text { Between } 5 \text { and } 10 \text { years }-23 \% \\
>10 \text { years }-23 \%\end{array}$ \\
\hline $\begin{array}{l}\text { Number of } \\
\text { perceived sounds }\end{array}$ & $\begin{array}{l}\text { Unique }-73 \% \\
\text { Multiple }-27 \%\end{array}$ \\
\hline
\end{tabular}

In bold, the most prevalent conditions.

scale. The total score for each scale analyzed is 44 points for the functional, 36 points for the emotional, and 20 points for the catastrophic scale. The scores can vary from 0 to 100 (points or \%) and correspond to a maximum loss of quality of life when they reach 100 points or $100 \%{ }^{14}$ Tinnitus annoyance was classified by the sum of points resulting from the Brazilian version of the THI and classified as slight (0-16\%), mild (18-36\%), moderate (38-56\%), severe (58-76\%), or catastrophic (78-100\%). ${ }^{27}$ The categories, slight and mild, as well as categories severe and catastrophic, were grouped to perform the statistical analysis.

Hearing loss was classified as follows: unilateral, bilateral, and symmetrical, and bilateral asymmetric losses.

For the epidemiological study of tinnitus in the sample studied, the occurrence of this symptom was analyzed by gender, age group, site affected by tinnitus (right ear, left ear, both ears, or head), frequency (sometimes, often, always), symptom onset $(<5$ years, between 5 and 10 years, $>10$ years), number of perceived sounds (single or multiple) and type of tinnitus reported. Data on the epidemiological study of tinnitus were described regarding frequency and percentage. The Fisher exact test was applied to analyze the association between the variables loudness and annoyance by tinnitus; start and loudness of tinnitus; beginning and annoyance by tinnitus; frequency and annoyance by tinnitus; hearing loss and loudness of tinnitus, and hearing loss and annoyance by tinnitus. The SAS software version 9.2 (SAS Institute Inc., Cary, NC, USA) was used, and a significance level of $5 \%$ was adopted. The Spearman correlation coefficient was applied to compare the VAS and THI values. ${ }^{28}$

\section{Results}

Of the 30 patients evaluated, 11 were male (36.7\%) and 19 were female (63.3\%). The ages ranged from 31 to 78 years old, with a mean of 56.5 years old (median $=58$ years old). The characterization of tinnitus for the studied series $(n=30)$ obtained in the interview is presented in -Table 1 .

The type of tinnitus reported by the patients was mostly "cricket" and "whistle" (30\%), followed by "wheezing" (23.3\%), "cicada” (20\%) and lesser "pressure cooker," "insect," "bird," "rain," "refrigerator," and "waterfall."

The following results were obtained regarding the classification of hearing loss: $13.3 \%$ of the patients had mild unilateral hearing loss, $43.4 \%$ mild bilateral symmetrical, $20 \%$ moderate bilateral symmetrical and $23.3 \%$ mild/moderate bilateral asymmetrical hearing loss.

The score of the VAS considered in this study were established as follows: mild ( 2 to $35 \mathrm{~mm}$ ), moderate (42 to $79 \mathrm{~mm}$ ), and severe (92 to $100 \mathrm{~mm}$ ).

Concerning the loudness of the tinnitus of the studied population, the VAS results showed that $43.5 \%$ of the patients presented mild, $36.5 \%$ presented moderate, and $20 \%$ presented severe loudness of the tinnitus. Regarding the annoyance by tinnitus according to the Brazilian version of the THI, $46.5 \%$ showed slightly/mild, $10 \%$ moderate, and $43.5 \%$ severe/ catastrophic discomfort. The categories slightly and mild, as well as the categories severe and catastrophic, were grouped for the accomplishment of the statistical analysis.

There was no association between loudness and annoyance by tinnitus ( $p=0.49$ ) ( - Table 2 ) and between the onset of tinnitus and loudness ( $p=0.9)$ ( - Table 3 ), but there was a significant association between the variables hearing loss and loudness $(p=0.03)$ ( $~-$ Table 4 ). There was no association between the variables onset and frequency of tinnitus as annoyance ([ $p=0.23$, (-Table 5]) and [ $p=0.63$, - Table 6], respectively), as there was no association between hearing loss and the annoyance by tinnitus ([ $p=0.39$, - Table 7$])$.

- Table 8 shows the mean values of the THI scores for each scale, in points and percentage, as well as the maximum

Table 2 Descriptive analysis and Fisher exact test results when there was association between loudness and annoyance by tinnitus $(n=30)$

\begin{tabular}{|l|l|l|l|l|l|}
\hline \multirow{2}{*}{ LOUDNESS } & \multicolumn{2}{|l|}{ ANNOYANCE } & \multirow{2}{*}{ Total } & \multirow{2}{*}{$p$-value } \\
\cline { 2 - 5 } & Slightly/Mild & Moderate & Severe/Catastrophic & \\
\hline Mild & $62 \%$ & $8 \%$ & $30 \%$ & $100 \%$ \\
\hline Moderate & $27 \%$ & $18 \%$ & $55 \%$ & $100 \%$ \\
\hline Severe & $50 \%$ & $0 \%$ & $50 \%$ & $100 \%$ \\
\hline Total & $14(46.7 \%)$ & $3(10 \%)$ & $13(43.3 \%)$ & $30(100 \%)$ \\
\hline
\end{tabular}


e194 Functional Impact of Tinnitus in Patients Mantello et al.

Table 3 Descriptive analysis and Fisher exact test results when there was association between the onset of tinnitus and loudness $(n=30)$

\begin{tabular}{|l|l|l|l|l|l|}
\hline \multirow{2}{*}{ ONSET OF TINNITUS } & \multicolumn{2}{|l|}{ LOUDNESS } & \multirow{2}{*}{ Total } \\
\cline { 2 - 5 } & Mild & Moderate & Severe & \\
\hline$<5$ years & $37 \%$ & $44 \%$ & $19 \%$ & $100 \%$ & 0.9 \\
\hline$>10$ years & $44 \%$ & $28 \%$ & $28 \%$ & $100 \%$ \\
\hline Between 5 and 10 years & $57 \%$ & $28 \%$ & $15 \%$ & $100 \%$ \\
\hline Total & $13(43.3 \%)$ & $11(36.7 \%)$ & $6(20 \%)$ & $30(100 \%)$ \\
\hline
\end{tabular}

Table 4 Descriptive analysis and Fisher exact test results when there was association between hearing loss and loudness of tinnitus $(n=30)$

\begin{tabular}{|l|l|l|l|l|l|}
\hline \multirow{2}{*}{ HEARING LOSS } & \multicolumn{2}{|l|}{ LOUDNESS } & \multirow{2}{*}{ Total } \\
\cline { 2 - 5 } & Mild & Moderate & Severe & \\
\hline (Normal/mild) Unilateral & $25 \%$ & $75 \%$ & $0 \%$ & $100 \%$ \\
\hline Mild bilateral symmetrical & $62 \%$ & $23 \%$ & $15 \%$ & $100 \%$ \\
\hline (Mild/moderate) bilateral asymmetrical & $14 \%$ & $72 \%$ & $14 \%$ & $100 \%$ \\
\hline Moderate bilateral symmetrical & $50 \%$ & $0 \%$ & $50 \%$ & $100 \%$ \\
\hline Total & $13(43.3 \%)$ & $11(36.7 \%)$ & $6(20 \%)$ & $30(100 \%)$ \\
\hline
\end{tabular}

*statistically significant value.

Table 5 Descriptive analysis and the Fisher exact test results when there was association between the onset of tinnitus and annoyance $(n=30)$

\begin{tabular}{|l|l|l|l|l|l|}
\hline \multirow{2}{*}{ ONSET OF TINNITUS } & \multicolumn{2}{|l|}{ ANNOYANCE } & \multirow{2}{*}{ Total } & \multirow{2}{*}{-value } \\
\cline { 2 - 5 } & Slightly/Mild & Moderate & Severe/Catastrophic & & \\
\hline$<5$ years & $56 \%$ & $19 \%$ & $25 \%$ & $100 \%$ & 0.23 \\
\hline$>10$ years & $29 \%$ & $0 \%$ & $71 \%$ & $100 \%$ & \\
\hline Between 5 and 10 years & $43 \%$ & $0 \%$ & $57 \%$ & $100 \%$ & \\
\hline Total & $14(46.7 \%)$ & $3(10 \%)$ & $13(43.3 \%)$ & $30(100 \%)$ & \\
\hline
\end{tabular}

Table 6 Descriptive analysis and the Fisher exact test results when there was association between tinnitus frequency and annoyance $(n=30)$

\begin{tabular}{|l|l|l|l|l|l|}
\hline \multirow{2}{*}{ FREQUENCY } & \multicolumn{2}{|l|}{ ANNOYANCE } & \multirow{2}{*}{ Total } & \multirow{2}{*}{-value } \\
\cline { 2 - 4 } & Slightly/Mild & Moderate & Severe/Catastrophic & & \\
\hline Often & $67 \%$ & $0 \%$ & $33 \%$ & $100 \%$ & 0.63 \\
\hline Do not know how to refer & $0 \%$ & $0 \%$ & $100 \%$ & $100 \%$ & \\
\hline Always & $50 \%$ & $13 \%$ & $37 \%$ & $100 \%$ & \\
\hline Sometimes & $0 \%$ & $0 \%$ & $100 \%$ & $100 \%$ & \\
\hline Total & $14(46.7 \%)$ & $3(10 \%)$ & $13(43.3 \%)$ & $30(100 \%)$ & \\
\hline
\end{tabular}

score for each of the scales. It was observed that all scales were scored at half the maximum allowable score, and, although the functional scale had the highest score, these results showed that tinnitus affected the quality of life of the subjects in a similar way among the evaluated spheres, namely functional, emotional, and catastrophic. There was a weak correlation between VAS and THI (Spearman correlation coefficient $=0.23$ ), as seen in -Fig. 1 .

\section{Discussion}

In our population, $60 \%$ presented bilateral tinnitus and, of them, $80 \%$ described the frequency of tinnitus as "always present." Moreover, most subjects (73\%) reported the perception of only one sound, and $27 \%$ referred to the perception of multiple sounds (two to four sounds reference) similar to previous studies. ${ }^{5,26,29}$ The types of tinnitus most reported 
Table 7 Descriptive analysis and Fisher exact test results when there was association between hearing loss and annoyance $(n=30)$

\begin{tabular}{|l|l|l|l|l|}
\hline \multirow{2}{*}{ LOSS } & \multicolumn{2}{|l|}{ ANNOYANCE } & \multirow{2}{*}{ Total } \\
\cline { 2 - 5 } & Slightly/Mild & Moderate & Severe/Catastrophic & \\
\hline (Normal/mild) Unilateral & $50 \%$ & $25 \%$ & $25 \%$ & $100 \%$ \\
\hline Mild bilateral symmetrical & $54 \%$ & $8 \%$ & $38 \%$ & $100 \%$ \\
\hline (Mild/moderate) bilateral asymmetrical & $14 \%$ & $14 \%$ & $72 \%$ & $100 \%$ \\
\hline Moderate bilateral symmetrical & $67 \%$ & $0 \%$ & $33 \%$ & $100 \%$ \\
\hline Total & $14(46.7 \%)$ & $3(10 \%)$ & $13(10 \%)$ & $30(100 \%)$ \\
\hline
\end{tabular}

Table 8 Mean values of the Tinnitus Handicap Inventory scores $(n=30)$

\begin{tabular}{|l|l|l|l|}
\hline Scales & Emotional & Functional & Catastrophic \\
\hline Values in points & 17.4 & 22.1 & 9.8 \\
\hline $\begin{array}{l}\text { Percentage } \\
\text { values }\end{array}$ & $48.33 \%$ & $50.15 \%$ & $49 \%$ \\
\hline $\begin{array}{l}\text { Maximum score } \\
\text { THI in points }\end{array}$ & 36 & 44 & 20 \\
\hline
\end{tabular}

Abbreviation: THI, Tinnitus Handicap Inventory.

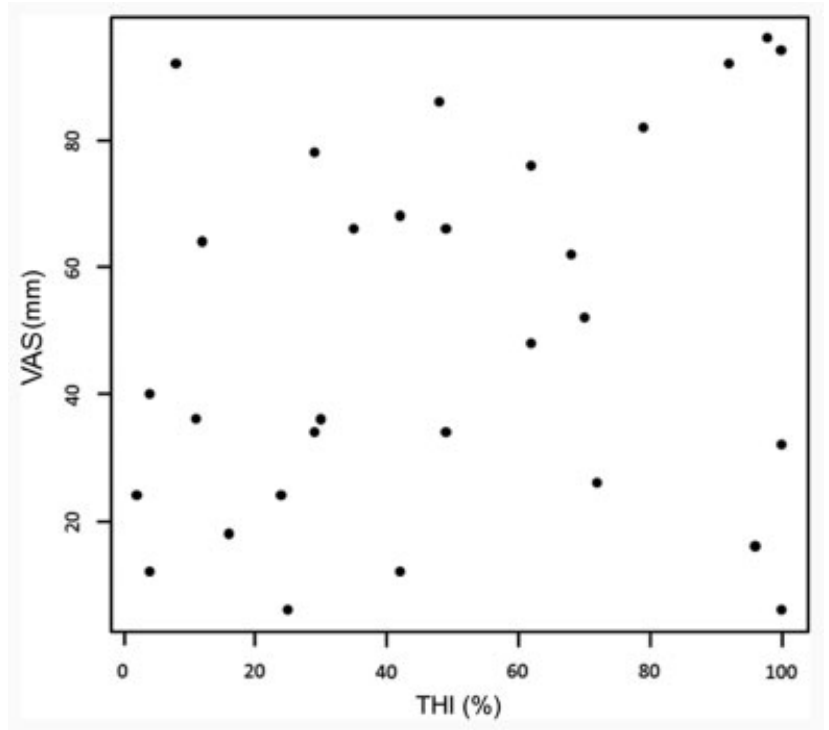

Fig. 1 Graphic representation of the Spearman correlation coefficient between the visual analogue scale (VAS) in millimeter $(\mathrm{mm})$ and the Tinnitus Handicap Inventory (THI) in percentage $(\%)(n=30)$.

by our patients, which was similar to the findings of other studies, had an acute pitch, like as "whistle" ${ }^{29}$ or "wheezing." ${ }^{30}$ Concerning the duration of tinnitus, most subjects (53\%) reported onset of less than 5 years prior to the study, and it is relevant to say that some authors consider the presence of tinnitus for more than 3 years as a chronic complaint. $^{26}$

Some of the factors that can aggravate the annoyance by tinnitus are the sensations related to the type of sound, constancy, duration, and location of tinnitus, as well as hearing loss. ${ }^{2}$ However, in our study, there was no statistically significant association between the variables onset of tinnitus and annoyance (THI) or onset of tinnitus and loud- ness (VAS), neither there was an association between frequency of tinnitus and annoyance (THI), revealing that subjectivity of tinnitus, the diversity of causes, and the heterogeneity of the affected subjects make this symptom quite complex, which justifies the great variability of results. This clearly shows that subjects with tinnitus are heterogeneous, and that several factors contribute to the impact of the symptom on the patient's life.

Hearing loss was analyzed regarding the variables loudness and annoyance by tinnitus, and our results showed that there was a significant association only between hearing loss and loudness. The only condition in which patients presented a statistically significant association with severe loudness was bilateral hearing loss, revealing that more than the degree of hearing loss itself, the involvement of both ears could significantly interfere with the loudness of tinnitus.

Even in the cases with loudness classified as mild, the annoyance was classified as severe/catastrophic. Some authors have reported correlations between the loudness of tinnitus and the severity of associated distress. ${ }^{31-33}$ Our main hypothesis was that loudness could be associated with the annoyance and the quality of life of the patient. However, this association was not observed in this study.

Unlike other studies, ${ }^{8,30}$ there was a weak correlation between the VAS and the THI. The presence of a correlation between these measures increases the credibility of the studies with the VAS, which is a more straightforward method and offers easier assimilation for the majority of the Brazilian population. ${ }^{15,30}$

All the subjects evaluated in this study presented impairment in their quality of life regarding emotional, functional, and catastrophic aspects, since all THI scales were scored at half the value of their maximum score. Most studies with THI did not mention the individual analysis of the scores of each scale. However, this analysis is essential, as it allows us to observe in the studied population which aspect is more or less affected in the quality of life and, in this way, to direct the more appropriate treatment for each case. Affirmative responses to specific items of the catastrophic scale, such as despair, loss of control, and fear of serious illness, warn the clinician that the patient may need referral to other professionals, such as psychologists or psychiatrists. ${ }^{9}$

The application of the THI during the diagnostic and therapeutic process can help with the self-perception of the subjects, as well as to quantify this symptom regarding the emotional, functional, and catastrophic aspects. 
The THI is a complete method of assessment, especially concerning the psychological and everyday aspects of tinnitus. However, using the two instruments together in clinical trials makes the results even more reliable. Subjects with tinnitus are heterogeneous, and several factors contribute to the impact of the symptom on the life of the patient. The complexity and heterogeneity of this population encourage more studies to evaluate the effects of this symptom on the quality of life, and to promote the early referral to specialized treatments (otorhinolaryngology, audiologist, psychology, and psychiatry), thus preventing the worsening of the symptom.

Research has described results in which the severity of tinnitus is associated with the severity of anxiety and depression disorders. ${ }^{30,34}$ Certain emotional disorders, such as anxiety and depression, are known to have important components in the medullary, pontine and mesencephalic levels of the brainstem, suggesting the hypothesis that the response of the limbic system to tinnitus may have a subcortical origin. There is a possibility of interactions between the dorsal cochlear nucleus (DCN) activity and other brainstem structures with the attentional and emotional components present in the perception of tinnitus. The hyperactivity of the DCN seems to contribute to the anxiety responses associated with tinnitus. These data highlight the need to include tools for the identification of anxiety and depression disorders in the diagnosis and treatment of tinnitus. ${ }^{35,36}$

This study has some limitations that should be mentioned. First, our sample was selected at the tinnitus outpatient clinic of a general hospital. Thus, the vast majority of the patients investigated had already been treated in other services without resolution of your problems, which could justify that even in the situations of mild loudness, some patients considered your annoyance as catastrophic. And finally, we do not investigate the relevance of the different etiologic factors for tinnitus loudness and annoyance. We included only patients with a sensorineural hearing loss, and some studies showed that conductive hearing loss and severe head injury had a stronger influence on loudness and annoyance. $^{8}$

The strengths of the present study were that we analyzed the association between different tinnitus-related characteristics with individual analysis of the scores of sub-scales of THI and the VAS. With this information, it is possible to better understand the functional impact on the quality of life of patients with tinnitus.

\section{Conclusion}

Tinnitus generated a level of annoyance in patients with hearing loss, in terms of catastrophic, functional, and emotional aspects, regardless of loudness, frequency, or time of onset. Hearing loss was a factor that interfered with the loudness of tinnitus. In the present study, we did not find a correlation between VAS and THI.

\section{Conflicts of Interest}

The authors declare that there are no conflicts of interest.

\section{References}

1 Person OC, Feres MCLC, Barcelos CEM, Mendonça RR, Marone MR, Rapoport PB. Zumbido: aspectos etiológicos, fisiopatológicos e descrição de um protocolo de investigação. Arq Med ABC. 2005; 30:111-118

2 Dias A, Cordeiro R, Corrente JE. Incômodo causado pelo zumbido medido pelo Questionário de Gravidade do Zumbido. Rev Saúde Públ. 2006;40:706-711

3 Pinto PC, Sanchez TG, Tomita S. The impact of gender, age and hearing loss on tinnitus severity. Rev Bras Otorrinolaringol (Engl Ed) 2010;76(01):18-24

4 Gomes SJ, Barboza MS, Santos TMM. A incidência de zumbido numa amostra aleatória na cidade de Salvador. Rev CEFAC 2004; 6:89-93

5 Sanchez TG, Bento RF, Minitti A, Câmara J. Tinnitus: Some Characteristics and Epidemiology. Clinical Experience from Clinics Hospital of São Paulo University. Bras J Otorhinolaryngol. 1997; 63:229-235

6 Azevedo AA, Oliveira AM, Siqueira AG, Figueiredo RR. A critical analysis of tinnitus measuring methods. Rev Bras Otorrinolaringol (Engl Ed) 2008;73:418-423

7 Schmidt LP, Teixeira VN, Dall'Igna C, Dallagnol D, Smith MM. Brazilian Portuguese Language version of the "Tinnitus Handicap Inventory": validity and reproducibility. Rev Bras Otorrinolaringol (Engl Ed) 2006;72(06):808-810

8 Hiller W, Goebel G. Rapid assessment of tinnitus-related psychological distress using the Mini-TQ. Int J Audiol 2004;43(10): 600-604

9 Newman CW, Jacobson GP, Spitzer JB. Development of the Tinnitus Handicap Inventory. Arch Otolaryngol Head Neck Surg 1996; 122(02):143-148

10 Castro ASO, Gazzola JM, Natour J, Ganança FF. [Brazilian version of the dizziness handicap inventory]. Pro Fono 2007;19(01):97-104

11 Zigmond AS, Snaith RP. The hospital anxiety and depression scale. Acta Psychiatr Scand 1983;67(06):361-370

12 Botega NJ, Bio MR, Zomignani MA, Garcia C Jr, Pereira WAB. Transtornos de humor em enfermarias de clínica médica e validação de escala de medida (HAD) de ansiedade e depressão. Rev Saúde Públ. 1995;29:355-363

13 Ooms E, Vanheule S, Meganck R, Vinck B, Watelet JB, Dhooge I. Tinnitus, anxiety and automatic processing of affective information: an explorative study. Eur Arch Otorhinolaryngol 2013;270 (03):823-830

14 Ferreira PEA, Cunha F, Onishi ET, Branco-Barreiro FCA, Ganança FF. Tinnitus handicap inventory: adaptação cultural para o Português brasileiro. Pró-Fono R Atual Cient. 2005;17:303-310

15 Barros Suzuki FA, Suzuki FA, Yonamine FK, Onishi ET, Penido NO. Effectiveness of sound therapy in patients with tinnitus resistant to previous treatments: importance of adjustments. Rev Bras Otorrinolaringol (Engl Ed) 2016;82(03):297-303

16 Geocze L, Mucci S, Abranches DC, Marco MA, Penido NdeO. Systematic review on the evidences of an association between tinnitus and depression. Rev Bras Otorrinolaringol (Engl Ed) 2013; 79(01):106-111

17 Araujo TdeM, lório MCM. Effects of sound amplification in selfperception of tinnitus and hearing loss in the elderly. Rev Bras Otorrinolaringol (Engl Ed) 2016;82(03):289-296

18 Schmidt LP, Teixeira VN, Dall'Igna C, Dallagnol D, Smith MM. Adaptação para a língua portuguesa do questionário Tinnitus Handicap Inventory: validade e reprodutibilidade. Rev Bras Otorrinolaringol 2006;72:808-810

19 Drexler D, López-Paullier M, Rodio S, González M, Geisinger D, Pedemonte M. Impact of reduction of tinnitus intensity on patients' quality of life. Int J Audiol 2016;55(01):11-19

20 Sanchez TG, Ferrari GMS. O controle do zumbido por meio de prótese auditiva: sugestões para otimização do uso. Pró-Fono R. Atual Cient. 2002;14:111-118 
21 Holgers KM, Zöger S, Svedlund K. Predictive factors for development of severe tinnitus suffering-further characterisation. Int J Audiol 2005;44(10):584-592

22 Holgers KM, Erlandsson SI, Barrenäs ML. Predictive factors for the severity of tinnitus. Audiology 2000;39(05):284-291

23 Baskill JL, Coles RRA. Relationship between tinnitus loudness and severity. In J. Hazell (Ed.). Sixth International Tinnitus Seminar, p. 424-428. Cambridge, United Kingdom: The Tinnitus and Hyperacusis Centre, 1999

24 Granjeiro RC, Kehrle HM, de Oliveira TS, Sampaio AL, de Oliveira CA. Is the degree of discomfort caused by tinnitus in normalhearing individuals correlated with psychiatric disorders? Otolaryngol Head Neck Surg 2013;148(04):658-663

25 Holgers K-M, Juul J. The suffering of tinnitus in childhood and adolescence. Int J Audiol 2006;45(05):267-272

26 Sanchez TG, Medeiros IRT, Levy CPD, Ramalho JdaR, Bento RF. Tinnitus in normally hearing patients: clinical aspects and repercussions. Rev Bras Otorrinolaringol (Engl Ed) 2005;71(04):427-431

27 McCombe A, Baguley D, Coles R, McKenna L, McKinney C, WindleTaylor P; British Association of Otolaryngologists, Head and Neck Surgeons. Guidelines for the grading of tinnitus severity: the results of a working group commissioned by the British Association of Otolaryngologists, Head and Neck Surgeons, 1999. Clin Otolaryngol Allied Sci 2001;26(05):388-393

28 Montgomery DC. Design and Analysis of Experiments. Nova Iorque: John Wiley \& Sons, Inc.; 2000
29 Moura LOS, Iorio MCM, Azevedo MF. A eficácia da adaptação de prótese auditiva na redução ou eliminação do zumbido. Rev Bras Otorrinolaringol 2004;70:624-631

30 Figueiredo RR, Azevedo AA, Oliveira PdeM. Correlation analysis of the visual-analogue scale and the Tinnitus Handicap Inventory in tinnitus patients. Rev Bras Otorrinolaringol (Engl Ed) 2009;75 (01):76-79

31 Meikle MB, Vernon J, Johnson RM. The perceived severity of tinnitus. Some observations concerning a large population of tinnitus clinic patients. Otolaryngol Head Neck Surg 1984;92 (06):689-696

32 Folmer RL, Griest SE, Meikle MB, Martin WH. Tinnitus severity, loudness, and depression. Otolaryngol Head Neck Surg 1999;121 (01):48-51

33 Unterrainer J, Greimel KV, Leibetseder M, Koller T. Experiencing tinnitus: which factors are important for perceived severity of the symptom? Int Tinnitus J 2003;9(02):130-133

34 Hiller W, Goebel G. Factors influencing tinnitus loudness and annoyance. Arch Otolaryngol Head Neck Surg 2006;132(12): 1323-1330

35 Langenbach M, Olderog M, Michel O, Albus C, Köhle K. Psychosocial and personality predictors of tinnitus-related distress. Gen Hosp Psychiatry 2005;27(01):73-77

36 Kaltenbach JA. The dorsal cochlear nucleus as a participant in the auditory, attentional and emotional components of tinnitus. Hear Res 2006;216-217:224-234 